Contribution from the Department of Inorganic Chemistry, Faculty of Sciences, and Department of Crystallography and Mineralogy and CSIC Department of Geologic Researches, Faculty of Sciences, University of Granada, 18071 Granada, Spain, and Department of Inorganic Chemistry, University College, Jaen, Spain

\title{
A Novel Type of Tetradentate Uracil Derivative in a Dodecahedral Eight-Coordinate Chelate Complex: catena-Bis $\left(\mu\right.$-6-amino-3-methyl-5-nitrosouracilato- $\left.N^{5}, O^{4}, N^{1}, O^{2}\right)$ cadmium(II)
}

\author{
Maria A. Romero, ${ }^{* 1 \mathrm{a}}$ Miguel N. Moreno, ${ }^{1 \mathrm{~b}}$ José Ruiz, ${ }^{1 \mathrm{a}}$ Maria P. Sảnchez, ${ }^{1 \mathrm{a}}$ and Fernando Nieto ${ }^{1 \mathrm{c}}$ \\ Received September 20, 1985
}

\begin{abstract}
The crystal structure of the complex catena-bis( $\mu$-6-amino-3-methyl-5-nitrosouracilato- $\left.N^{5}, O^{4}, N^{1}, O^{2}\right)$ cadmium(II) has been determined. It crystallizes in the tetragonal space group $P 4_{1} 2{ }_{1} 2-D_{4}^{4}$ with cell dimensions $a=b=7.885(0) \AA, c=26.359$ (2) $\AA$, $V=1638.8$ (1) $\AA^{3}$, and $Z=4$. The structure was solved from diffractometer data by Patterson and Fourier methods and refined by full-matrix least squares to $R=0.018$ for 1956 data. The structure consists of a sequence of complex polymeric sheets, linked by hydrogen bonds. Each ligand is coordinated to two different cadmium atoms, and each cadmium atom is coordinated by four pyrimidine ligands. These ligands are equivalent with one cadmium atom binding through N5 and $\mathrm{O} 4$ atoms, while the other cadmium atom binds through the $\mathrm{N} 1$ and $\mathrm{O} 2$ sites. The cadmium atom is eight-coordinated and shows a $C_{2}$ symmetry that can be described as a dodecahedron with the $\mathrm{mmmm}$ arrangement of ligands. The A vertices are all occupied by oxygen atoms and the $\mathrm{B}$ vertices by nitrogen atoms.
\end{abstract}

\section{Introduction}

The interactions of metal ions with nucleic acids in general and cytosine, uracil, thymine, and their derivatives in particular have been extensively studied over the past few years, ${ }^{2-6}$ while there are considerably fewer reports of structural studies of 5-nitrosopyrimidine derivatives.

Crystallographic studies on metal complexes of cytosine, uracil, and thymine indicate that metal binding sites are the nitrogen atoms of the pyrimidine ring when these atoms are available, but in some cases, chelate formation through the adjacent exocyclic group takes place. This is particularly common in the metal complexes of 5-nitrosopyrimidine derivatives. X-ray works on complexes with nitrosopyrimidines, all of them referred to violuric ${ }^{7}$ and 1,3-dimethylvioluric ${ }^{8}$ acids, have shown binding at N5 and one adjacent oxygen atom. Only in the complex $\mathrm{Sr}(\mathrm{HVi})_{2} \cdot 4 \mathrm{H}_{2} \mathrm{O}$ does the binding not take place through N5. In this complex the violurato anion is coordinated to $\mathrm{Sr}$ (II) through $\mathrm{O} 5$ and one ketonic oxigen atom. ${ }^{7 a}$

In the course of our studies on the coordinating pattern of some pyrimidine derivatives ${ }^{9}$ we have isolated and characterized a number of these metal complexes. In the present paper the crystal structure of the complex catena-bis $(\mu$-6-amino-3-methyl-5nitrosouracilato- $\left.N^{5}, O^{4}, N^{1}, O^{2}\right)$ cadmium(II) (Cd(AMNU) $)_{2}$ ) is described in order to determine the coordination properties of a nitrosouracil derivative with the $\mathrm{N} 3$ position blocked.

\section{Experimental Section}

Data Collection. The complex $\mathrm{Cd}(\mathrm{AMNU})_{2}$ was synthesized according to the method previously reported. ${ }^{9_{\mathrm{a}}}$

Experimental data for the determination of crystal structure have been collected at the "CNR Centro di Studio per la Cristallografia Strutturale" of the Universitá di Pavia, Pavia, Italy.

A red crystal (dimensions $0.48 \times 0.38 \times 0.32 \mathrm{~mm}^{3}$ ) was chosen for the X-ray measurements. Crystal data were taken at room temperature on a Philips PW-1100 four-circle diffractometer using graphite-monochromatized Mo K $\alpha$ radiation $(\lambda=0.7107 \AA) ; \mu=13.712 \mathrm{~cm}^{-1}$

Cell parameters were determined from 27 high-angle reflections, with use of a locally improved version of the Philips LAT routine that allows a fast and accurate determination of the $d$ spacings by determining the center of gravity of the reflections in a row of the reciprocal space passing through the origin only if their intensities exceed a predeterminated counting threshold: $a=b=7.8850$ (3) $\AA, c=26.359$ (2) $\AA, d_{\text {calcd }}=$ $1.826 \mathrm{~g} \cdot \mathrm{cm}^{-3}, Z=4$, formula weight 450.6 .

Space Group Determination and Intensity Data. A set of precession photographs showed the tetragonal Laue symmetry, and the systematic absences $(h 00, h=2 n ; 00 l, l=4 n)$ were consistent with space groups $P 4_{1} 2_{1} 2$ and $P 4_{3} 2_{1} 2$. For the exact determination of the space group, four equivalent tetragonal reflections $(h k l, k h l, \bar{h} k l$, and $\bar{k} h l)$ were collected. When the four reflections were averaged, 1476 equivalent reflections were

* To whom all correspondence should be addressed. obtained, 271 of which $[I \leqslant 5 \sigma(I)]$ were considered unobserved. The final refinements were realized for both space groups with use of both real and imaginary components of anomalous dispersion. ${ }^{10}$ Only noncentrosymmetric equivalent reflections $(h k l / \bar{k} h l$ and $k h l / \bar{h} k l)$ were averaged. So 2389 equivalent reflections were obtained, 1956 of which [ $I$ $>5 \sigma(I)]$ were used for calculation, which led to an $R$ value of $0.018\left(R_{w}\right.$ $=0.021)$ for $P 4_{1} 2_{1} 2$ and $0.021\left(R_{w}=0.024\right)$ for $P 4_{3} 2{ }_{1} 2$, respectively. Therefore $P 4_{1} 2_{1} 2$ was assumed.

Intensity data were collected by using the $\omega$-scan mode, in the range $2^{\circ}<\theta<30^{\circ}$, at a $2 \theta$ scan rate of $0.03 \mathrm{~s}^{-1}$ and a total scan width of $1.2^{\circ}$. The reflection intensities were corrected for Lorentz and polarization factors and then for absorption by following the semiempirical method of North et al. ${ }^{11}$ (maximum and minimum absorption corrections 1.1451 and 0.9962)

Structure Determination and Refinement. The coordinates of the cadmium atom were found in a three-dimensional Patterson synthesis. The other non-hydrogen atoms were located by subsequent steps on Fourier maps. Full-matrix least-squares refinements were then carried out for the non-hydrogen atoms. The coordinates of the hydrogen atoms of the methyl and amino groups were idealized (XANADU) ${ }^{12}$ and were found on a difference Fourier map. The non-hydrogen atoms were refined anisotropically; the hydrogen atoms were assigned isotropic thermal parameters, $B_{\text {eq }}=5.0 \AA^{2}$. The analytical scattering factors of ref 10 were used throughout the analysis.

(1) (a) Department of Inorganic Chemistry, University of Granada. (b) University College. (c) Department of Crystallography and Mineralogy and CSIC Department of Geologic Researches, University of Granada.

(2) Hodgson, D. J. Prog. Inorg. Chem. 1977, 23, 211

(3) Marzilli, L. G. Prog. Inorg. Chem. 1977, 23, 255

(4) Gellert, R. W.; Bau, R. Met. Ions Biol. Syst. 1979, 8, 1-55.

(5) Martin, R. B.; Mariam, Y. H. Met. Ions Biol. Syst. 1979, 8, 57-1 24.

(6) Lippert, B. Platinum, Gold, and Other Metal Chemotherapeutic Agents; ACS Symposium Series 209; American Chemical Society: Washington, DC, $1983 ; \mathrm{p} 147$, and references therein.

(7) (a) Hamelin, M. C.R. Seances Acad. Sci., Ser. C 1967, 264, 2034. (b) Hamelin, M. Ibid. 1968, 266, 19. (c) Raston, C. L.; White, H. J. Chem. Soc., Dalton Trans. 1976, 1915. (d) Abraham, F.; Nowogrocki, G.; Sueur, S. Acta Crystallogr., Sect. B: Struct. Crystallogr. Cryst. Chem. 1978, $B 34,1466$

(8) (a) Romero-Molina, M. A.; Martin-Ramos, J. D.; Lôpez-Gonzâlez, J. D.; Valenzuela-Calahorro, C. An. Quim., Ser. B 1983, 79, 200. (b) Ruiz-Valero, C.; Monge, A.; Gutiérrez-Puebla, E.; Gutiérrez-Rios, E. Acta Crystallogr., Sect. C: Cryst. Struct. Commun. 1983, C39, 1214. (c) Ibid. 1984, C40, 811. (d) Moreno, M. N.; Salas, J. M.; Colacio, E.; Sánchez, M. P. Ibid., in press.

(9) (a) Moreno-Carretero, M. N.; Salas-Peregrin, J. M. J. Therm. Anal. 1984, 29, 1053. (b) Salas-Peregrin, J. M.; Moreno-Carretero, M. N.; Colacio-Rodriguez, E. Can. J. Chem. 1985, 63(12), 3573. (c) SalasPeregrin, J. M.: Moreno-Carretero, M. N.: Romero-Molina, M. A.; Colacio-Rodriguez, E. Rev. Chim. Miner. 1984, 2I, 233.

(10) International Tables for $X$-ray Crystallography; Kynoch: Birmingham, England, 1974; Vol. 4.

(11) North, A. C. T.; Phillips, D. C.; Mathews, F. S. Acta Crystallogr., Sect. A: Cryst. Phys., Diffr., Theor. Gen. Crystallogr. 1968, A24, 351

(12) Roberts, P.; Sheldrick, G. M. "XANADU 1975, Program for Crystallographic Calculations"; University of Cambridge: Cambridge, England, 1975. 
Table I. Fractional Atomic Coordinates $\left(\times 10^{4}\right)$, Equivalent Isotropic Thermal Parameters, and Anisotropic Thermal Parameters $\left(\times 10^{4}\right)$ for Non-Hydrogen Atoms ${ }^{a, b}$

\begin{tabular}{|c|c|c|c|c|c|c|c|c|c|c|}
\hline atom & $x / a$ & $y / b$ & $x / c$ & $B_{\text {eq }}, \AA^{2}$ & $\beta_{11}$ & $\beta_{22}$ & $\beta_{33}$ & $\beta_{23}$ & $\beta_{13}$ & $\beta_{12}$ \\
\hline $\mathrm{Cd}$ & $18819(2)$ & $1881.9(2)$ & $0(0)$ & $1.82(0)$ & $63(0)$ & $63(0)$ & $8(0)$ & $0(0)$ & $0(0)$ & $0(0)$ \\
\hline N1 & $8971(2)$ & $1865(3)$ & $66(0)$ & $2.53(4)$ & $64(3)$ & $155(3)$ & $8(0)$ & $0(1)$ & $1(1)$ & $2(3)$ \\
\hline $\mathrm{C} 2$ & 8707 (3) & $1491(3)$ & 564 (1) & $2.37(6)$ & $77(4)$ & $107(5)$ & $9(0)$ & $3(1)$ & $0(1)$ & $4(3)$ \\
\hline $\mathrm{O} 2$ & $9897(2)$ & $1282(3)$ & 849 (1) & $3.34(6)$ & $90(3)$ & $191(4)$ & $11(0)$ & $7(1)$ & $-6(1)$ & $11(3)$ \\
\hline N3 & $7027(3)$ & $1318(3)$ & $746(1)$ & $2.60(5)$ & $76(3)$ & $159(4)$ & $7(0)$ & $9(1)$ & $0(1)$ & $1(3)$ \\
\hline $\mathrm{C} 3$ & $6768(4)$ & $928(5$ & 1285 (1) & $4.37(9)$ & $127(5)$ & $307(8)$ & $8(0)$ & $23(1)$ & $1(1)$ & $4(6)$ \\
\hline C4 & 5625 & $1527(3)$ & 443 (1) & $2.07(5)$ & $72(3)$ & $95(4)$ & $8(0)$ & $2(1)$ & $0(1)$ & $0(3)$ \\
\hline $\mathrm{O} 4$ & $4180(2)$ & $1369(2)$ & $622(1)$ & $2.52(4)$ & $79(3)$ & $136(3)$ & $8(0)$ & $7(1)$ & $4(1)$ & $-4(2)$ \\
\hline C5 & $5957(3)$ & $1932(4)$ & $-86(1)$ & $2.21(5)$ & $65(3)$ & $131(4)$ & $6(0)$ & $2(1)$ & $1(1)$ & $-2(3)$ \\
\hline N5 & $4567(2)$ & $2110(3)$ & $-373(1)$ & $2.58(5)$ & $74(3)$ & $160(5)$ & $7(0)$ & $3(1)$ & $1(1)$ & $-1(3)$ \\
\hline O5 & $4728(3)$ & $2450(3)$ & -839 (1) & $4.23(7)$ & $113(3)$ & $325(7)$ & $6(0)$ & $11(1)$ & $-2(1)$ & $0(3)$ \\
\hline C6 & $7686(3)$ & $2093(4)$ & $-225(1)$ & $2.63(6)$ & $79(4)$ & $159(6)$ & $7(0)$ & $0(1)$ & $3(1)$ & $0(3)$ \\
\hline N6 & $8014(3)$ & $2433(4)$ & $-732(1)$ & $4.50(8)$ & $86(3)$ & $377(9)$ & $7(0)$ & $10(1)$ & $3(1)$ & $-6(5)$ \\
\hline H31 & 5910 & 1830 & 1420 & & & & & & & \\
\hline H32 & 6040 & -150 & 1290 & & & & & & & \\
\hline H33 & 7820 & 360 & 1380 & & & & & & & \\
\hline H61 & 8990 & 2530 & -850 & & & & & & & \\
\hline H62 & 7260 & 2770 & -920 & & & & & & & \\
\hline
\end{tabular}

${ }^{a}$ The form of the anisotropic temperature factor is exp $\left[-\left(\beta_{11} h^{2}+\beta_{22} k^{2}+\beta_{33}{ }^{2}+2 \beta_{12} h k+2 \beta_{13} h l+2 \beta_{23} k l\right)\right]{ }^{b}$ The estimated standard deviations of the last significant figures are given in parentheses, all tables and in the text.

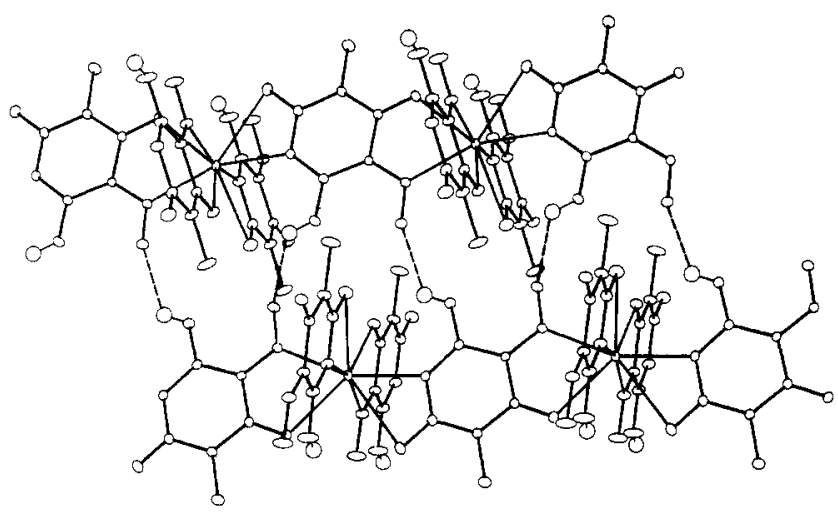

Figure 1. Section of the crystal structure of $\mathrm{Cd}(\mathrm{AMNU})_{2}$.

The PARST program ${ }^{13}$ was used for calculating molecular parameters; figures were drawn with ORTEP II. ${ }^{14}$

Final positional parameters and anisotropic thermal parameters are collected in Table I.

\section{Results and Discussion}

A section of the crystal structure of the polymeric $\mathrm{Cd}(\mathrm{AMNU})_{2}$ compound is displayed in Figure 1. A view of one fragment of the polymeric network is shown in Figure 2, and the geometry of the coordinated ligand is drawn in Figure 3. Selected interatomic distances and angles around the cadmium atom and conformational parameters are listed in Tables II and III, respectively.

The structure consists of piled complex sheets in which each cadmium atom is coordinated by four pyrimidine derivatives (AMNU) in the anionic form and each ligand is coordinated by two different cadmium atoms.

The AMNU ligands are equivalent with one cadmium atom binding to the $\mathrm{N} 5$ and $\mathrm{O} 4$ atoms, while the other cadmium atom binds to the $\mathrm{N} 1$ and $\mathrm{O} 2$ sites. Thus, 6-amino-3-methyl-5nitrosouracilate acts as a tetradentate ligand as it is depicted in Figure 2. The Cd(AMNU) ${ }_{4}{ }^{2-}$ anion exhibits a crystallographic $C_{2}$ symmetry. The $C_{2}$ axis passing through the midpoints of the opposite $b$ edges $^{15 \mathrm{a}}$ connects atoms $\mathrm{N} 5$ and $\mathrm{N} 5^{\mathrm{i}}$ and atoms $\mathrm{N} 1^{\text {ii }}$ and $\mathrm{N}^{\mathrm{iii}}$ (Figure 4). Within experimental error the four ligands occupy two planes that are mutually perpendicular (see Table III) and contain the cadmium atom.

(13) Nardelli, M. Comput. Chem. 1983, 7, 95.

(14) Johnson, C. K. "ORTEP II", Report ORNL-5138; Oak Ridge National Laboratory: Oak Ridge, TN, 1976.

(15) For a description of dodecahedral vertex and edge nomenclature, see: (a) Hoard, J. L.; Silverton, J. V. Inorg. Chem. 1963, 2, 235. (b) Drew, M. G. B. Coord. Chem. Rev. 1977, 24, 179.
Table II. Bond Distances $(\AA)$ and Angles (deg) around Cadmium for $\mathrm{Cd}(\mathrm{AMNU})_{2}{ }^{a}$

\begin{tabular}{|c|c|c|c|}
\hline $\mathrm{Cd}-\mathrm{N} 5$ & $2.341(2)$ & $\mathrm{Cd}-\mathrm{N} 1$ & $2.302(2)$ \\
\hline $\mathrm{Cd}-\mathrm{O} 4$ & $2.478(2)$ & $\mathrm{Cd}-\mathrm{O}_{2}$ & $2.773(2)$ \\
\hline $\mathrm{N} 5-\mathrm{Cd}-\mathrm{N} 5^{\mathrm{i}}$ & $92.15(12)$ & $\mathrm{N} 1^{\mathrm{ii}}-\mathrm{Cd}-\mathrm{O} 4$ & $132.71(6)$ \\
\hline $\mathrm{N} 5-\mathrm{Cd}-\mathrm{N} 1^{\mathrm{ii}}$ & $159.05(7)$ & $\mathrm{N} 1^{\mathrm{ii}}-\mathrm{Cd}-\mathrm{O} 4^{\mathrm{i}}$ & $83.78(7)$ \\
\hline $\mathrm{N} 5-\mathrm{Cd}-\mathrm{N} 1^{\mathrm{iii}}$ & $92.87(8)$ & $\mathrm{N} 1^{i i}-\mathrm{Cd}-\mathrm{O} 2^{\mathrm{ii}}$ & $51.33(6)$ \\
\hline $\mathrm{N} 5-\mathrm{Cd}-\mathrm{O} 4$ & $68.23(6)$ & $\mathrm{N} 1^{\mathrm{ii}}-\mathrm{Cd}-\mathrm{O}^{2 \mathrm{ii}}$ & $83.54(7)$ \\
\hline $\mathrm{N} 5-\mathrm{Cd}-\mathrm{O} 4^{\mathrm{i}}$ & $79.25(7)$ & $\mathrm{O} 4-\mathrm{Cd}-\mathrm{O}_{4}^{\mathrm{i}}$ & $132.62(8)$ \\
\hline $\mathrm{N} 5-\mathrm{Cd}-\mathrm{O} 2^{\mathrm{ii}}$ & $149.61(6)$ & $\mathrm{O} 4-\mathrm{Cd}-\mathrm{O}^{2 \mathrm{ii}}$ & $81.38(6)$ \\
\hline $\mathrm{N} 5-\mathrm{Cd}-\mathrm{O}_{2}^{\mathrm{iii}}$ & $81.87(7)$ & $\mathrm{O} 4-\mathrm{Cd}-\mathrm{O} 2^{\mathrm{iij}}$ & $124.58(6)$ \\
\hline $\mathrm{N} 1^{\mathrm{ii}}-\mathrm{Cd}-\mathrm{N} 1^{\mathrm{iii}}$ & $89.66(12)$ & $\mathrm{O} 2^{\mathrm{ii}}-\mathrm{Cd}-\mathrm{O} 2^{\mathrm{iii}}$ & $117.36(9)$ \\
\hline
\end{tabular}

${ }^{a}$ Symmetry transformations: (i) $y, x,-z$; (ii) $x-1, y, z$; (iii) $y, x-$ $1,-z$. In all text, these transformations will be named in the same way.

Table III. Conformational Parameters of Cd(AMNU) 2

(a) Least-Squares Mean Planes of the Form $A x+B y+C z+D=0^{a}$

\begin{tabular}{|c|c|c|c|c|c|}
\hline $\begin{array}{c}\text { plane } \\
\text { no. }\end{array}$ & atoms & $A$ & $B$ & $C$ & $D$ \\
\hline \multicolumn{6}{|c|}{ Complex Plane } \\
\hline P1 & $\mathrm{O} 4, \mathrm{Cd}, \mathrm{N} 5$ & 0.1031 & 5.2524 & 1.1819 & -7.9476 \\
\hline P2 & $\mathrm{O}_{4}^{\mathrm{i}}, \mathrm{Cd}, \mathrm{N}^{\mathrm{i}}$ & 5.2524 & 0.1031 & -1.1819 & -7.9476 \\
\hline P3 & $\mathrm{N} 1^{\mathrm{ii}}, \mathrm{Cd}, \mathrm{O}^{2 \mathrm{ii}}$ & -0.0523 & -4.8628 & -1.0646 & 7.2940 \\
\hline P4 & $\mathrm{N} 1^{\mathrm{iii}}, \mathrm{Cd}, \mathrm{O} 2^{\mathrm{iij}}$ & -4.8628 & -0.0523 & 1.0646 & 7.2940 \\
\hline \multicolumn{6}{|c|}{ Ligand Plane } \\
\hline P5 & $\begin{array}{l}\mathrm{N} 1, \mathrm{C} 2, \mathrm{~N} 3, \\
\mathrm{C} 4, \mathrm{C} 5, \mathrm{C} 6\end{array}$ & $0.017(1$ & $-0.975(0)$ & $-0.221(1)$ & $1.358(6)$ \\
\hline
\end{tabular}

(b) Atoms and Their Displacements from Plane P5 $(\AA)$ $\mathrm{N} 1,0.003$ (2); C2, -0.003 (3); N3, 0.001 (2); C4, -0.000 (2); C5, 0.000 (3); C6, -0.003 (3); Cd, $-0.065 ;$ O2, 0.007 ; C3, $-0.016 ; \mathrm{O} 4,-0.003 ; \mathrm{N} 5,0.013 ; 05,0.025 ; \mathrm{N} 6,0.018$

(c) Dihedral Angles (deg)

\begin{tabular}{rrlr}
\hline planes & angle & planes & angle \\
\hline P1/P2 & 89.38 & P2/P3 & 88.97 \\
P1/P3 & 0.60 & P2/P4 & 0.60 \\
P1/P4 & 88.97 & P3/P4 & 88.56
\end{tabular}

${ }^{a} x, y$, and $z$ are orthogonal coordinates measured in angstroms along $a, b$, and $c$, respectively, of the crystallographic coordinate system. Symmetry transformations are given in Table II.

The $\mathrm{Cd}$ atoms are eight-coordinated (Figure 2) with four nitrogen and four oxygen atoms bound to the metal. As indicated by Drew, ${ }^{15 b}$ the values of $\phi$ angles are a good test for the determination of the shape of the coordination polyhedron. The $\phi$ angles, calculated by using the HSM shape characteristics, are 


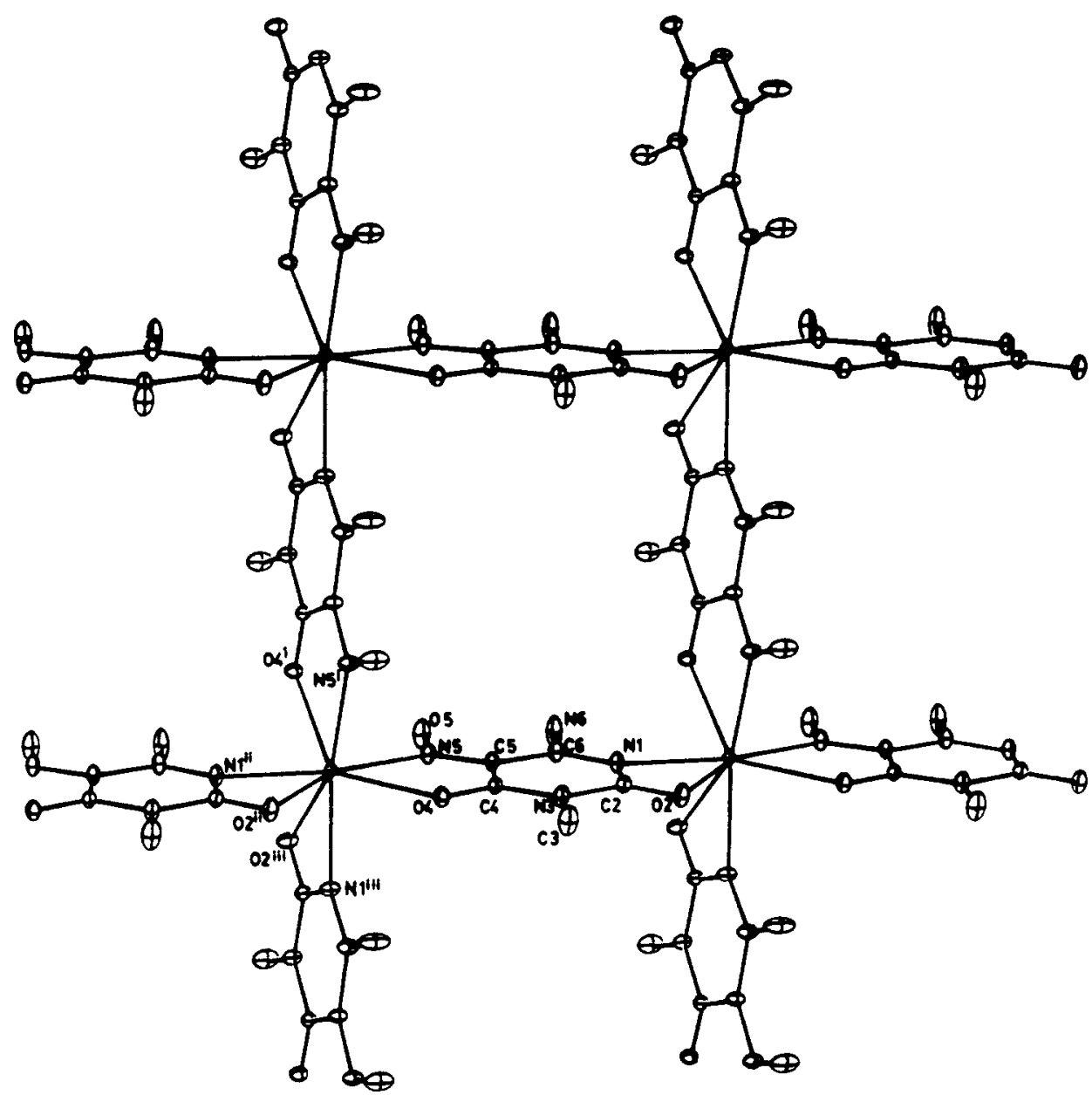

Figure 2. View, in the plane $a b$, of one fragment of the polymeric network in $\mathrm{Cd}(\mathrm{AMNU})_{2}$. The drawings were performed with use of the program ORTEP. ${ }^{14}$

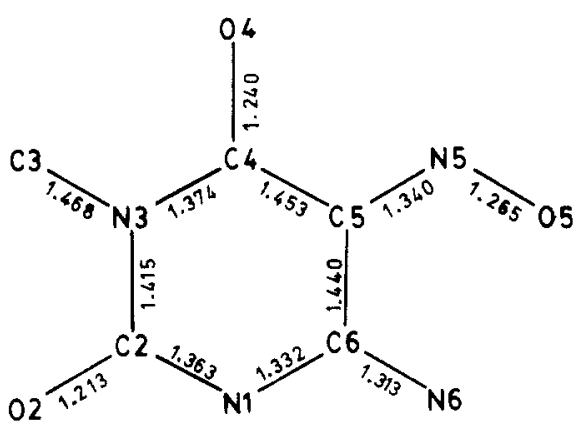

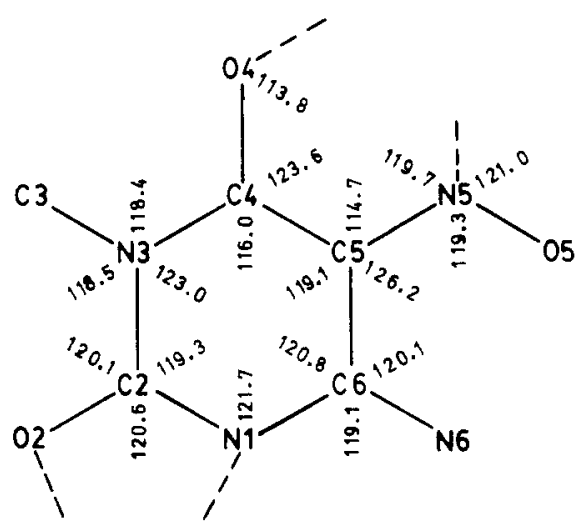

Figure 3. Interatomic distances and bond angles of the coordinated ligand. The esd's are $0.002-0.004 \AA$ for bond lengths and $0.1-0.2^{\circ}$ for bond angles.

0.0 and $24.5^{\circ}$ for the dodecahedron and the square antiprism, respectively. In this case, both $\phi$ values are $0.1^{\circ}$, which indicates that the coordination polyhedron is best described as a distorted dodecahedron with the $m m m m$ arrangement of ligands. ${ }^{15 a}$ The angles ${ }^{15 \mathrm{a}} \theta_{\mathrm{A}}$ and $\theta_{\mathrm{B}}$ have the mean values 40.7 and $79.5^{\circ}$.

The most interesting feature of the structure is that the nitrogen and oxygen atoms do not sort between the A and B sites, as suggested by Orgel's rule; ${ }^{16}$ thus, the oxygen atoms are in the $A$ sites and the nitrogen atoms are in the B sites (Figure 4). This event is in agreement with the conclusion of Lippard, ${ }^{17}$ which says that the distribution of ligand atoms among the $\mathbf{A}$ and $\mathbf{B}$ positions may reflect to some extent the need for the metal atom to accumulate or give up negative charge through $\pi$ bonding.

(16) Steffen, W, L.; Fay, R. C. Inorg. Chem. 1978, 17, 2120.

(17) Lippard, S. J. Prog. Inorg. Chem. 1967, 8, 109.
Moreover, in our case the four N...O contacts along the $m$ edges (2.238-2.705 $\AA$, Figure 4) are short compared with the van der Waals contact of $2.90 \AA$ for the same atoms, which could influence the donor atom sorting pattern and the choice of stereoisomer.

Cadmium-oxygen bond distances of 2.478 (2) and 2.773 (2) $\AA$ agree well with the corresponding distances of 2.286 and 2.682 $\AA$ in the dodecahedral anion $\left[\mathrm{Cd}(\mathrm{OAc})_{4}\right]^{2-18}$ and are on the margin of those found in $\mathrm{Cd}(1 \mathrm{MeC})_{2} \mathrm{Cl}_{2}{ }^{19 \mathrm{a}}$ and $\left[\mathrm{Cd}\left(5^{\prime}-\right.\right.$

(18) Langs, D. A.; Hare, C. R. Chem. Commun. 1967, 890.

(19) (a) Gagnon, C.; Beauchamp, A. L. Can. J. Chem. 1979, 57, 1372. (b) Shiba, J. K.; Bau, R. Inorg. Chem. 1978, 17, 3484. (c) Mutikaien, I.: Lumme, P. Acta Crystallogr. Sect. B: Struct. Crystallogr. Cryst. Chem. 1980, B36, 2237. (d) Goodgame, D. M. L.; Jeeves, I.; Reynold, C. D.; Skapski, A. C. Biochem. J. 1975, 151, 467. (e) Clark, G. R. Orbell, J. D. Acta Crystallogr., Sect. B: Struct. Crystallogr. Cryst. Chem. 1978, B34, 1815. 


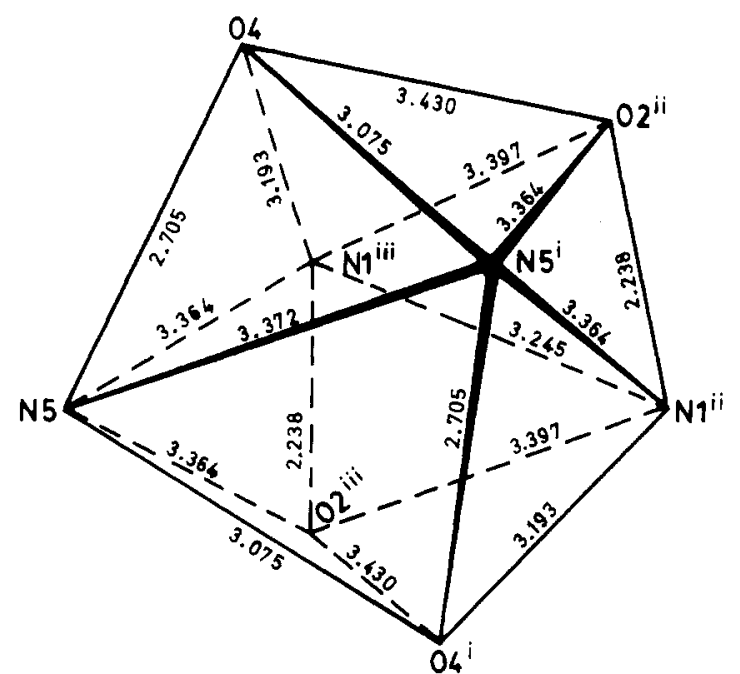

Figure 4. Polyhedral edge lengths $(\AA)$ of $\mathrm{Cd}(\mathrm{AMNU})_{4}{ }^{2-}$ anions. The four short edges of length 2.238 and $2.705 \AA$ are the dodecahedral $m$ edges spanned by the four bidentate ligands.

CMP) $\left.\left(\mathrm{H}_{2} \mathrm{O}\right)\right]_{n}^{19 \mathrm{~b}}(2.58-2.87 \AA)$.

The Cd-N distances of 2.302 (2) and 2.341 (2) $\AA$ are in the normal range observed in other similar cadmium complexes with pyrimidine derivatives $(2.21-2.34 \AA) .{ }^{19}$

The AMNU ligands are essentially planar (Table III) with the exocyclic atoms deviating somewhat. The cadmium atom deviates to a greater extent, $-0.065 \AA$ from the near plane through the ring atoms.
The geometry of the ligand (Figure 3 ) is in agreement with that reported for this ligand in the complex [ $\left.\mathrm{Zn}(\mathrm{AMNU})_{2}\left(\mathrm{H}_{2} \mathrm{O}\right)_{2}\right] \cdot$ $2 \mathrm{H}_{2} \mathrm{O}^{8 \mathrm{~d}}$ in spite of the fact that, in this case, the ligand is bidentate (N5, O4), being bound by neither $\mathrm{O} 2$ nor $\mathrm{N} 1$ with the $\mathrm{Zn}$ (II) ion.

A very interesting aspect of this structure is the tetradentate character of the ligand. Thus far, this is the first metal complex of uracil derivatives that is found to involve $\mathrm{N} 5, \mathrm{O} 4, \mathrm{~N} 1$, and $\mathrm{O} 2$ atoms, causing the uracil derivative to act as a bridging ligand.

The packing within the crystal is such as to produce an infinite planar network. Different networks are held together by hydrogen bonds formed between one proton of an amino group and the O5 atom of one nitroso group of position $x+1 / 2,-y+1 / 2,-z-1 / 4$. The N6-O5 and O5...H61 distances are 2.797 (3) and 2.215 (3) $\AA$, respectively. These separations are smaller than 2.9 and 2.6 $\AA$ (sums of the van der Waals radii of $\mathrm{N}$... O and $\mathrm{H} . . \mathrm{O}$, respectively) suggested by $\mathrm{Ladd}^{20}$ as a criterion for the existence of a hydrogen bond.

Acknowledgment. We are indebted to R. Oberti and L. Ungaretti for their collaboration.

Registry No. Cd(AMNU) $)_{2}, 100494-96-0$.

Supplementary Material Available: According to policy instituted Jan 1,1986 , the tables of calculated and observed structure factors (19 pages) are being retained in the editorial office for a period of 1 year following the appearance of this work in print. Inquiries for copies of these materials should be directed to the Editor.

(20) Ladd, M. F. Structure and Bonding in Solid State Chemistry; Ellis Hawood: New York, 1979.
Contribution from the Department of Chemistry, Massachusetts Institute of Technology, Cambridge, Massachusetts 02139

\section{Dioxomolybdenum(VI)-Substituted 2,6-Pyridinedimethanol} Complexes: New Five-Coordinate Species

Joel M. Hawkins, John C. Dewan, and K. Barry Sharpless*

\section{Received October 7, 1985}

Dioxomolybdenum(VI) complexes with sterically bulky ligands have attracted recent interest as molybdoenzyme models. ${ }^{1,2}$ Our interest in this area lies in the development of new asymmetric oxidation catalysts. While exploring the utility of threo- $\alpha, \alpha-$ di-tert-butyl-2,6-pyridinedimethanol (1) as a new $C_{2}$ symmetric chiral ligand, we prepared the corresponding dioxomolybdenum(VI) complex. X-ray crystallographic analysis revealed a novel five-coordinate $\mathrm{MoO}_{2} \mathrm{NO}_{2}$ structure, which we describe herein.

\section{Results}

Pyridinediol 1 was prepared in a single pot from 2,6-dibromopyridine by two successive lithiation and pivalaldehyde trap cycles (eq 1). ${ }^{3}$ The threo isomer 1, distinguished by the presence of two peaks on chiral stationary phase HPLC, ${ }^{4}$ was readily separated from the meso isomer 2 by flash chromatography. ${ }^{5}$

(1) (a) Berg, J. M.; Holm, R. H. J. Am. Chem. Soc. 1985, 107, 917. (b) Berg, J. M.; Holm, R. H. Ibid. 1985, 107, 925.

(2) Subramanian, P.; Spence, J. T.; Ortega, R.; Enemark, J. H. Inorg. Chem. 1984, 23, 2564.

(3) Martin's pyridine $N$-oxide lithiation and in situ trapping procedure followed by deoxygenation with triphenylphosphine (10 equiv, neat, 220 ${ }^{\circ} \mathrm{C}, 1 \mathrm{~h}$ ) also works here. Taylor, S. L.; Lee, D. Y.; Martin, J. C. J. Org. Chem. 1983, 48, 4156.

(4) Pirkle, W. H.; Finn, J. M. J. Org. Chem. 1981, 46, 2935.

(5) Still, W. C.; Kahn, M.; Mitra, A. J. Org. Chem. 1978, 43, 2923.

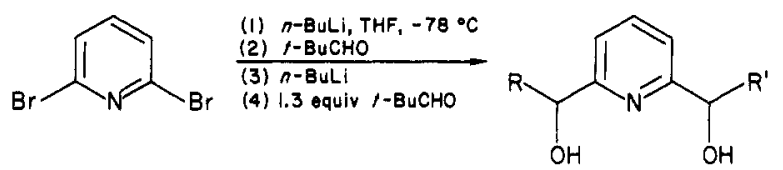

$(R, R)-1, R=\alpha-t-B u, R^{\prime}=\beta-\gamma-B u$ $(S, S)-1, R=\beta-t-B u, R^{\prime}=\alpha-t-B u$ 2. $R=R^{\prime}=a \cdot t-B u$

Resolution was accomplished by multiple recrystallizations of the dibenzoyltartrate salt. The analogous threo-diisopropyl ligand was prepared similarly but not resolved.

Dioxomolybdenum(VI) complexes were prepared from the corresponding pyridinediols by reaction with $\mathrm{MoO}_{2}(\mathrm{acac})_{2}$ in dichloromethane followed by removal of volatiles in vacuo and recrystallization from dichloromethane/ether. Pertinent spectroscopic data are given in Table I. The solid-state IR spectra $(\mathrm{KBr})$ show a similarity between the racemic $t$-Bu and racemic $i$-Pr complexes, 4 and 7, with Holm's unsubstituted complex $3 .^{6}$ The homochiral $t$-Bu and meso-t-Bu complexes, 5 and 6 , in contrast, do not show the band near $850 \mathrm{~cm}^{-1}$. The solution-state IR spectra, taken in bromoform due to its transparency in the $\nu_{\mathrm{MoO}}$ region, are the same for the substituted complexes 4-7, each lacking the band near $850 \mathrm{~cm}^{-1}$. Similar solution-state behavior among the substituted complexes is also seen in the ${ }^{1} \mathrm{H}$ NMR spectra $\left(\mathrm{CDCl}_{3}\right)$. The molecular weight of the homochiral $t-\mathrm{Bu}$ complex 5 , measured in dichloromethane by the Signer method,? indicated it to be monomeric in solution.

Crystals of the homochiral $t$-Bu complex 5 suitable for X-ray crystallography were grown by slow evaporation of a dichloromethane solution. Crystallography revealed two discrete mono-

(6) Berg, J. M.; Holm, R. H. Inorg. Chem. 1983, 22, 1768

(7) Clark, E. P. Ind. Eng. Chem., Anal. Ed. 1941, $13,820$. 